\title{
Hypolipidamic study of ethyl acetate leaves extract of Momordica charantia on the biochemical parameters of Streptozotocin-Nicotinamide induced type 2 diabetic rats.
}

\author{
Abraham Ubhenin ${ }^{1}$, Fatima Amin Adamude ${ }^{1}$, Emeka John Dingwoke ${ }^{*}$, Nwobodo Ndubuisi \\ Nwobodo ${ }^{3,4}$ \\ ${ }^{1}$ Department of Biochemistry, Federal University, Lafia, Nigeria \\ ${ }^{2}$ Department of Biochemistry, Ahmadu Bello University, Zaria, Nigeria \\ ${ }^{3}$ Department of Pharmacology and Therapeutics, Enugu State University of Science and Technology, Enugu, Nigeria \\ ${ }^{4}$ Department of Pharmacology and Therapeutics, College of Health Sciences, Nile University of Nigeria, FCT, Abuja, \\ Nigeria
}

\begin{abstract}
Objective: To evaluate antidiabetic potential of Momordica charantia leaves extract on StreptozotocinNicotinamide induced type 2 diabetic rats.

Methods: Eighteen mice were used for acute toxicity while thirty rats used were for the Hypolipidamic study. They were grouped into five of six rats per group. Group 1 normal control received $5 \%$ tragacanth, Group 2 the diabetic-induced untreated received 5\% tragacanth only, Group 3 diabeticinduced received $50 \mathrm{mg} / \mathrm{kg}$ body weight standard drug glibenclamide, Group 4 diabetic-induced received $50 \mathrm{mg} / \mathrm{kg}$ body weight methanolic extract of Momordica charantia, and Group 5 diabetic induced received $50 \mathrm{mg} / \mathrm{kg}$ body weight ethyl acetate fraction of Momordica charantia. The induction of type 2 diabetes was by single intraperitoneal injection of $120 \mathrm{mg} / \mathrm{kg}$ body weight, $60 \mathrm{mg} / \mathrm{kg} \mathrm{body} \mathrm{weight}$ Streptozotocin. Rats with fasting blood glucose above $200 \mathrm{mg} / \mathrm{dl}$ were considered hyperglycemic. Blood samples were collected for biochemical analysis; the liver tissue was used for hisotopathologic analyses. Methanolic leaves extract of Momordica charantia was obtained by cold maceration with $5 \mathrm{~L}$ methanol for 72 hours at room temperature and fractionated.

Results: Oral treatment with the extracts caused significant reduction $(P<0.05)$ in the blood glucose levels. The serum levels of the biochemical parameters; urea, creatinine, alpha-amylase and lipid profiles that were negatively altered by the induction became significantly improved due to treatment with the extract. The liver histomorphology also improved.

Conclusion: These findings suggest that leaves extract of ethyl acetate fraction of Momordica charantia possesses antidiabetic properties with insulin-mimicking action and could be used for the treatment of diabetic disorder.
\end{abstract}

Keywords: Hypoglycemia, Type 2 diabetes, Drugs, Side effects, Streptozotocin, Nicotinamide, Momordica charantia leaves.

Accepted on May 06, 2019

\section{Introduction}

Diabetes Mellitus is a group of metabolic disorders characterized by chronic hyperglycemia due to impairment of insulin secretion, insulin action, or both, resulting in an uncoordinated carbohydrate, lipid, and protein metabolism [1]. Generally, the insulin-dependent diabetes mellitus, otherwise known as type 1 diabetes mellitus and non-insulin-dependent diabetes mellitus, known as type 2 diabetes mellitus are the two forms of diabetes. The type 2 is the most common form suffered by 90 to $95 \%$ of all diabetic patients [2]. The prevalence of type 2 diabetes mellitus has been predicted to increase to 439 million by 2030 [3] if not curtailed. Genetic factor and life style are possible factors that cause diabetes, while obesity and sedentary life style are the predisposing factors [4]. Study of the epidemiological characteristics of type 2 diabetes mellitus revealed a steady increase in the developed countries, such as United States and Japan with majority of the victims within the age of 45-64 years [5]. Statistical data indicated that seven out of top ten countries with the largest number of diabetic patients are from low- or middle-income countries [5], Nigeria is an example. Another emerging 
epidemic of type 2 diabetes mellitus is the rising rates of childhood obesity which is becoming more common in children, teenagers and adolescents [6].

Treatment for type 2 diabetes mellitus remains a health challenge, considering the increasing cases of drug resistance, high cost and several side effects such as lactic acidosis, gastrointestinal (GI) effects such as nausea, vomiting diarrhea and flatulence associated with Metformin [7], higher rate of hypoglycemia associated with Sulphonyl ureas [8], increased risk of bladder cancer associated with Thiazolidinediones [9], abdominal bloating, diarrhea and flatulence associated with $\alpha$ Glucosidase inhibitors [10], acute pancreatitis and renal dysfunction associated with Glucagon-like peptide-1 receptor agonists [11]. These side effects caused by the use of synthetic drugs motivated the search for effective antidiabetic agents with little or no side effects from medicinal plants.

According to the World Health Organization, a medicinal plant is a plant in which one or more of its organs contains substances that can be used for therapeutic purposes, or which are precursors for chemo-pharmaceutical semi-synthesis. Such plants are in great demand by pharmaceutical companies for their active ingredients [12]. Momordica charantia is an indigenous medicinal plant belonging to the family Cucurbitaceae. It is commonly known as bitter gourd or bitter melon in English. Tradomedically, the fruit, stems, leaves and roots of Momordica charantia have been used for treatments of ailments such as microbial infections including those caused by Escherichia coli, Salmonella, Staphylococcus aureus, Staphylococcus, Pseudomonas, and Streptobaccilus [13], hyperlipidemia, digestive disorders, and menstrual abnormalities [14]. It has been reported that Momordica charantia possesses powerful antiviral properties against white spot syndrome virus and human immunodeficiency virus $[15,16]$. The anti-carcinogenic properties of Momordica charantia have also been reported $[16,17]$. It is has been established that researcher' $s$ interest for scientific investigations on plant based system is motivated by the bioactive secondary metabolites produced either by the fruit, seeds, leaves, roots and or bark parts of the plant [18]. The tradomedical use of plant-based system is emerging but needs scientific verification to validation the practice. Animal models of type-2 diabetes have been proved to be useful for studying the pathogenesis and research for novel therapy for the disease [1]. The experiment described in the paper is the first report on the hypoglycemic activities and insulin-mimicking action of ethyl acetate fraction of Momordica charantia on Streptozotocin-nicotinamade induced hyperglycemic rat models.

\section{Material and Methods}

\section{Chemicals and reagents}

All chemicals and reagents used for this experiment were of analytical grade and purchased from Sigma-Aldrich Chemical Co. (St. Louise, MO, USA).

\section{The plant materials and preparation of crude extracts}

Leaves of Momordica charantia were obtained from a farm at Igueben in Igueben Local Government Area of Edo StateNigeria. It was identified and authenticated by the Botanists at the Forest Research Institute of Nigeria (FRIN), Ibadan. The plant material was then deposited at the FRIN Herbarium for reference purpose. The leaves were washed with clean tap water and dried under shade at room temperature for 14 days. The dried leaves was pulverized into powder using electric blender (pye Unicam, Cambridge, England) and stored in a polythene bag until needed.

The crude sample was obtained by soaking $300 \mathrm{~g}$ of the powered leaves sample in $5 \mathrm{~L}$ of methanol with few drops of chloroform and extracted by cold maceration for 48 hours using soxhlet extractor. The methanol extract was filtered using a Buchner funnel and Whatman No.1 filter paper. Dried methanolic extract was obtained after removing the solvent by evaporation under reduced pressure using rotary evaporator, the concentrated extract was weighed and the percentage yield calculated using the formula thus:

Percentage yield $=$ Mass yield of extract/Mass of plant material $\times 100$

This crude extract was stored in an air-tight container and kept in the refrigerator at $4^{\circ} \mathrm{C}$ until used for the experiment.

\section{Partitioning of crude extract}

The methanol extract was separately suspended in $80 \mathrm{~mL}$ methanol and $20 \mathrm{~mL}$ distilled water in a separating funnel (1L). $200 \mathrm{~mL}$ of petroleum ether was added to the methanol extract in the separating funnel. The mixture was slightly agitated and the pressure accumulated in the funnel was released by opening the tap. The mixture was allowed to stand for a few minutes and the ether layer collected. The recovered methanol extract was again treated with $200 \mathrm{~mL}$ of petroleum ether and separated. This procedure was repeated until a total of $7 \mathrm{~L}$ of petroleum ether became used. The petroleum ether portions and the methanol were together evaporated to dryness. The recovered methanol extract was then extracted with $2.5 \mathrm{~L}$ of chloroform followed by $3 \mathrm{~L}$ of ethyl acetate, following the same procedure. Successive partitioning with petroleum ether $\left(40-60^{\circ} \mathrm{C}\right)$, chloroform and ethyl acetate in this order of polarities afforded three fractions of the extract. These various fractions were concentrated to dryness, weighed and the percentage yield recorded. Extract spoilage was prevented by preserving in the desiccator.

\section{Animals}

Following institutional ethics approval (ethical approval number ABUCAUC/2018/029), albino rats were obtained from the department of Veterinary Pharmacology and Toxicology, Ahmadu Bello University, Zaria. All the animal care and treatment procedure were strictly observed following the guidelines established by the University's committee on animal use and care. Adult male wistar rats weighing 100-120 g were 
used for the experiments. The animals were maintained under normal laboratory conditions of humidity, temperature, and light for 7 days prior to the investigations and allowed access to food (grower's mass, vital feed) and water ad libitum.

\section{Oral acute toxicity}

Oral acute toxicity of the Momordica charantia was carried out following the guidelines set by Lorke [19]. Adult albino mice weighing $30 \mathrm{~g}$ were randomly divided into 6 groups of 3 mice per cage. The experiment was in two phases. Phase one was done using Groups 1, 2 and 3. They were administered 10, 100 and $1000 \mathrm{mg} / \mathrm{kg}$ body weight of the extract respectively. Phase two was done using Groups 4, 5 and 6, they received 1600, 2900 and $5000 \mathrm{mg} / \mathrm{kg}$ body weight of the extract respectively. The extract (suspended in $0.6 \%$ carboxy methyl cellulose CMC) was administered orally to the mice. The animals were observed behaviorally (alertness, restlessness, irritability, and fearfulness), neurologically (spontaneous activity, respiratory rate, reactivity, touch response, pain response, heart rate and blood pressure, and gait), and autonomically (defecation and urination) for 24 hours. After a period of 24 hours, the animals were observed for 14 days for mortality. The animals were observed for mortality up to 48 hour (acute) and for another 14 days for sub chronic toxicity [20]. The median lethal dose $\left(\mathrm{LD}_{50}\right)$ was calculated using geometric mean as the square root of the product of the lowest lethal dose and the highest nonlethal dose.

$\mathrm{LD}_{50}=\sqrt{\mathrm{XY}}$

" $\mathrm{X}$ " was the highest dose without death, and "Y" was the lowest dose with death.

\section{Animal grouping}

The animals were shared in five groups of six animals in a cage thus:

Group 1: (Normal control) received 5\% tragacanth orally daily for thirty days.

Group 2: (Diabetic control) received 5\% tragacanth orally daily for thirty days.

Group 3: (Diabetic standard) received $50 \mathrm{mg} / \mathrm{kg}$ body weight Glibenclamide orally daily for thirty days.

Group 4: (Diabetic treated) received $50 \mathrm{mg} / \mathrm{kg}$ body methanolic extract of Momordica charantia orally daily for thirty days.

Group 5: (Diabetic treated) received $50 \mathrm{mg} / \mathrm{kg}$ body weight ethyl acetate fraction of Momordica charantia orally daily for thirty days.

\section{Induction of type 2 diabetes mellitus}

Hyperglycemia was induced according to the method described [21]. The rats were fasted overnight prior to induction of diabetes by a single intraperitoneal administration of $60 \mathrm{mg} / \mathrm{kg}$ body weight streptozotocin, 15 minutes after intraperitoneal injection of $120 \mathrm{mg} / \mathrm{kg}$ body weight nicotinamide. Hyperglycemia was then confirmed by measuring the fasting blood level after 24 hours induction using a glucometer. The rats with fasting blood level above $200 \mathrm{mg} / \mathrm{dl}$ were considered as having type 2 diabetes and were included for this study. To prevent hypoglycemic mortality, the animals received 5\% w/v glucose solution ( $2 \mathrm{ml} / \mathrm{kg}$ body weight) after 24 hours of Streptozotocin and Nicotinamide injection. Blood was collected into fluoride oxalate and heparinized tubes from the tail of the rats after making incision with surgical blade and it was used for the estimation of the fasting blood glucose levels. This was done on the 2nd, 7th, 21st and 30th days' of the treatments. However, after 24 hours of the last treatment, the overnight fasted animals were anaesthetized with chloroform and then sacrificed by cervical decapitation. Blood was collected by cardiac puncture with needle syringe into plain tubes and allowed to clot. Both tubes were centrifuged 4000 rpm for $15 \mathrm{~min}$ to obtain plasma and sera which were used for the analysis. The liver and kidney tissues were collected and wash with normal saline and stored at $-80^{\circ} \mathrm{C}$.

\section{Histological analysis of the liver tissues}

The histological examination of the hepatocytes was carried out according to Banchroft et al. [22]. Tissues of the various groups were fixed in $10 \%$ formolsaline $(\mathrm{pH}=7.2)$ for 24 hours. Serial sections of $4 \mathrm{~mm}$ thickness was obtained using a rotatory microtome and then the tissue sections were collected on glass slides, dehydrated by immersing in serial dilutions of ethanol with distilled water, cleaned in xylene and embedded in paraffin wax. The specimens were deparaffinized and stained with hematoxylin and eosin (H\&E) dye for histopathological examinations. Photomicrographs of the tissue sections were captured using charge-coupled device (CCD) camera under light microscope (Olympus BX51TF; Olympus Corporation, Tokyo, Japan) at 400x magnification.

\section{Estimation of biochemical parameters}

Estimation of serum total proteins, albumin, urea, creatinine and amylase: Serum total protein in the blood serum was estimated by the biuret reaction according to the method of Reinhold [23] using Sigma protein assay kit. Principle of the assay is based on the reaction of proteins and peptides with cupric ions in alkaline solutions to form a violet complex which is read spectrometrically at $546 \mathrm{~nm}$. Three test tubes were set up, $0.1 \mathrm{ml}$ of the sample was pipetted into the test tube A (sample), $0.1 \mathrm{ml}$ of the standard was pipetted into test tube B (standard), $0.1 \mathrm{ml}$ distilled water was in test tube C (blank) and $5 \mathrm{ml}$ biuret reagent were pipetted into each of the test tube. The reaction mixtures were mixed properly by vortexing and allowed to stand for 30 minutes at room temperature. The absorbance of the sample and the standard were measured against the blank at $546 \mathrm{~nm}$ using a table top Shimadzu spectrophotometer. The total protein concentration was calculated thus:

Total protein concentration $(\mathrm{g} / \mathrm{l})=$ Absorbance of sample $\times$ Concentration of standard $(70 \mathrm{~g} / \mathrm{l}) /$ Absorbance of standard. 
Albumin urea was estimated according to the method of Natelson et al. [24].

Principle of the assay is based on reaction of albumin with bromocresol green in the presence of detergents in a blue-green complex measured using spectrophotometer. Exactly $0.02 \mathrm{ml}$ of the sample was pipetted into test tube A (sample), $0.02 \mathrm{ml}$ into test tube B (standard), $0.02 \mathrm{ml}$ distilled water was pipetted into test tube $\mathrm{C}$ (blank), then $2 \mathrm{ml}$ of the reagent was pipetted into each of the test tubes. The mixtures were allowed to stand for 10 minutes at room temperature before reading the absorbance of the sample, standard at $600 \mathrm{~nm}$ against the blank. The albumin concentration was calculated thus:

Albumin Concentration $(\mathrm{g} / \mathrm{l})=$ Absorbance of sample $\times$ Concentration of standard (40 g/l)/Absorbance of standard

Serum creatinine was determined creatinine assay kit according to Jaffe's reaction as described by Roscoe [25]. The principle is based on the reaction of creatinine and picric acid in an alkaline medium forming an orange color complex that absorbs at $520 \mathrm{~nm}$.

Serum amylase was estimated using alpha-amylase the assay kit as described by Klein and Foreman [26]. The principle is based on the cleavage of alpha-amylase into soluble colored product by an insoluble dye-coupled substrate amylose azure. The color intensity was measured at $595 \mathrm{~nm}$.

Estimation of lipid profile: The serum level of triglyceride was determined using serum triglyceride assay kit, following the method described by Tietz [27]. The principle was based on the quinoeimine dye produced by the peroxidase-catalyzed coupling of 4-aminoantipyrine (4-AAP) and sodium N-ethyl$\mathrm{N}$-(3-sulfopropyl)m-anisidine (ESPA) with $\mathrm{H}_{2} \mathrm{O}_{2}$, which absorbed at $540 \mathrm{~nm}$. The increase in absorbance at $540 \mathrm{~nm}$ is directly proportional to glycerol (and triglyceride) concentration of the sample.

Serum total cholesterol assay kit was used to determine the total cholesterol according to the method described by Siedel [28]. The principle is based on the hydrolysis of cholesterol esters to free cholesterol and fatty acids by cholesterol esterase. Cholesterol oxidase then oxidizes the free cholesterol cholesten-3-one and hydrogen peroxide. Reaction of hydrogen peroxide with 4-aminoantipyrine and phenol catalyzed by peroxidase formed colored quinoneimine product measured at $520 \mathrm{~nm}$.

High density lipoprotein cholesterol (HDL-cholesterol) was estimated colorimetrically according to the method described by Sugiuchi [29] using the assay kit. The reaction principle is based on the reaction of HDL-cholesterol with polyethylene glycol-cholesterol oxidase, which produced hydrogen peroxide. The hydrogen peroxide reacted with 4aminoantipyrine and 3-alpha-hydroxysteroid dehydrogenase under the action of peroxidase to form a purple/blue pigment that is measured at $600 \mathrm{~nm}$.

The Serum level of low density lipoprotein cholesterol (LDLC) was estimated as described Friedewald et al. [30] very low density lipoprotein cholesterol (VLDL-C) was estimated by the method of Morita et al. [31] atherogenic index (AI) was determined as described by Dobiasova and Frohlich [32] and coronary risk index (CRI) were determined following the method of Alladi and Shanmugasundaram [33].

Estimation of glycogen contents in liver and kidney tissues: The glycogen content of liver and kidney were estimated based on the method described by Maiti et al. [34]. Each of the Samples was homogenized in $80 \%$ ethanol at the concentration of $100 \mathrm{mg} \mathrm{mL}^{-1}$ then centrifuged at $10,000 \mathrm{rpm}$ for $25 \mathrm{~min}$. The sediment was dried in a water bath. $5 \mathrm{~mL}$ and $6 \mathrm{~mL}$ of distilled water and perchloric acid were added to the dried sample for further extraction at $4^{\circ} \mathrm{C}$ for $20 \mathrm{~min}$. This was centrifuged at 10,000 rpm for $15 \mathrm{~min}$ and the supernatant was removed. Exactly $0.2 \mathrm{~mL}$ of the supernatant was measured into test tube and the volume was made up to $1 \mathrm{~mL}$ with distilled water. Same concentration of glycogen standard was made with a volume of $1 \mathrm{~mL}$. Exactly $4 \mathrm{~mL}$ of anthrone reagent was then added to each tube and incubated at $95^{\circ} \mathrm{C}$ in a boiling water bath for $10 \mathrm{~min}$. The absorbances of the samples were measured at $630 \mathrm{~nm}$ after cooling the tube at room temperature. The amount of glycogen in tissue samples was expressed in microgram of glucose per milligram tissue.

\section{Statistical analysis}

All the data were expressed as mean \pm SEM. Statistical significance between the groups were tested using one-way analysis of variance (ANOVA) followed by Dunnett's t-test post-hoc test. P-value less than 0.5 was considered significant.

\section{Results}

Result of the acute toxicity study indicated that extract caused no adverse reactions or death of the mice. Intraperitoneal injection of Streptozotocin in the animals caused a significant $(p<0.05)$ abnormal lipid profiles characterized by increases in serum triglycerides, total cholesterol, low density lipoprotein accompanied by decrease of serum level of high density lipoprotein (Figure 1). The atherogenic index AI, and coronary risk index were also increased significant $(\mathrm{p}<0.05)$ in diabetic rats. Treatment with Glibenclamide, methanolic extract of Momordica charantia and ethyl acetate fraction of Momordica charantia resulted to a normal levels of lipid profiles and atherogenic index AI, and coronary risk index. The hypoglycemic effect of ethyl acetate fraction of Momordica charantia in Streptozotocin-Nicotinamide induced diabetic rats is presented in table 1. Hyperglycemia was observed as indicated in the fasting blood glucose of the diabetic control rats after the intraperitoneal administration of $50 \mathrm{mg} / \mathrm{kg}$ body weight Streptozotocin and $120 \mathrm{mg} / \mathrm{kg}$ body weight Nicotinamide. Oral treatment of the rats with Glibeclamide (standard group) and the extracts (methanolic extract group) and the ethyl acetate group resulted in the significant reduction $(\mathrm{P}<0.05)$ in the blood glucose levels, compared to the diabetic control (untreated) group. Compared to the standard group, the ethyl acetate fraction of the extract was more bioactive than the methanolic extract. The reduction started on day 7 and continues up to day 30 of the experiment. 
Hypolipidamic study of ethyl acetate leaves extract of Momordica charantia on the biochemical parameters of Streptozotocin-Nicotinamide induced type 2 diabetic rats

Table 2 presents the hypolipidemic effect of ethyl acetate fraction of Momordica charantia on StreptozotocinNicotinamide induced diabetic rats. The hyperlipidemia observed in the diabetic control was indication of diabetic condition, but upon oral treatment with standard drug Glibeclamide and the methanolic and ethyl acetate extracts, hypolipidemia was achieved in the treated groups compared to the diabetic control (untreated) group.

Data on table 3 is the effect of ethyl acetate fraction of Momordica charantia on the biochemical parameters on

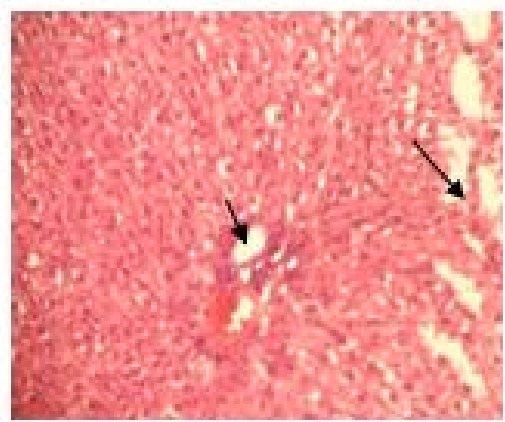

A

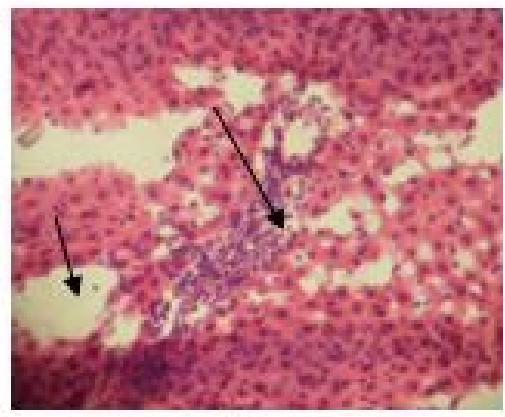

C
Streptozotocin-nicotinamide induced diabetic rats. As seen on the diabetic control (untreated) group, the Streptozotocinnicotinamide tampered with the liver biomarker enzymes. Upon oral treatment with the standard drug glibenclimide and the extract at a dose of $50 \mathrm{mg} / \mathrm{kg}$ body weight, the liver total protein, total kidney creatinine, serum urea and liver glycogen were all restored towards normal levels. The ethyl acetate fraction had more restorative effect on the biochemical parameters compared to the standard drug and the methanolic extract (Table 4).

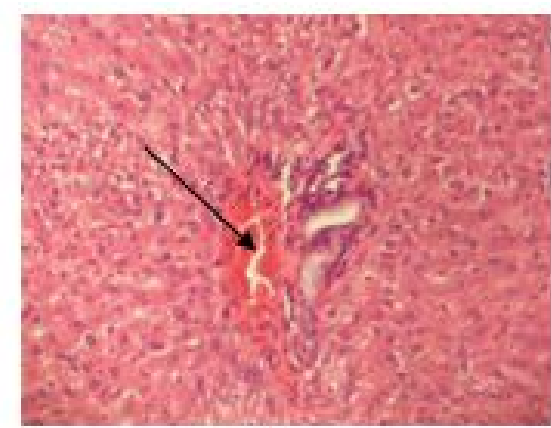

B

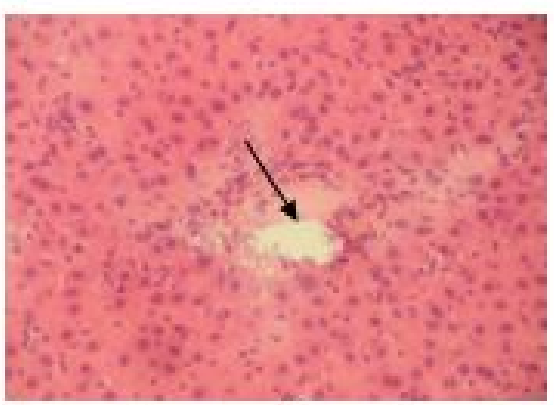

D

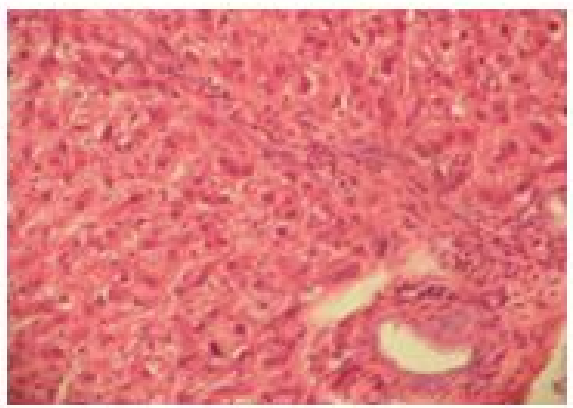

$\mathbf{E}$

Figure 1. Histopathology of the animals hepatocytes (photograph of Hematoxylin and Eosin (H\&E)) different sections were stained with paraffin. (A): Control: Normal rat liver composed of normal hepatocytes A, sinusoids B central vein C and bile duct D (H\&E 100x). (B): Streptozotocin/ Nicotinamide induced diabetic rat liver showing focal intimal erosion A, and vascular congestion B (H\&E 100x). (C): Streptozotocin/ Nicotinamide induced diabetic rat liver treated with Glibeclamide showing mild focal intimal erosion A, and vascular congestion B (H\&E $100 x$ ). (D): Streptozotocin/ Nicotinamide induced diabetic rat liver treated with methanol extract of Momordica charantia showing mild focal intimal erosion A, and vascular congestion B (H\&E 100x). (E): Streptozotocin/ Nicotinamide induced diabetic rat liver treated with ethyl acetate fraction of extract of Momordica charantia showing a normal liver architecture (H\&E 100x). 
Table 1. Hypoglycemic effect of ethyl acetate fraction of Momordica charantia in Streptozotocin-Nicotinamide induced diabetic rats.

\begin{tabular}{|c|c|c|c|c|c|}
\hline Parameters & Day 0 & Day 7 & Day 14 & Day 21 & Day 30 \\
\hline Normal control & $72 \pm 5.6$ & $74 \pm 4.71$ & $77 \pm 5.82$ & $79 \pm 7.31$ & $75 \pm 7.84$ \\
\hline Diabetic control & $211 \pm 12.6^{a}$ & $252 \pm 10.22^{a}$ & $285 \pm 25.6^{a}$ & $311 \pm 35.3^{a}$ & $309 \pm 45.3^{a}$ \\
\hline Diabetic+Glibeclamide & $206 \pm 7.66^{\mathrm{a}}$ & $140 \pm 13.74^{\mathrm{ab}}$ & $98 \pm 8.4^{b}$ & $63 \pm 9.6^{b}$ & $61 \pm 7.5^{b}$ \\
\hline Diabetic $+M$. charantia & $215 \pm 10.0^{a}$ & $172 \pm 16.82^{\mathrm{ab}}$ & $127 \pm 11.5^{\mathrm{ab}}$ & $98 \pm 6.8^{b}$ & $88 \pm 8.4^{b}$ \\
\hline Diabetic+ethyl acetate fraction & $218 \pm 9.73^{a}$ & $125 \pm 7.50^{\mathrm{ab}}$ & $107 \pm 9.7^{a b}$ & $75 \pm 7.84^{b}$ & $53 \pm 6.2^{\mathrm{ab}}$ \\
\hline
\end{tabular}

Data is expressed as Mean $\pm S D$ for six rats in each group. ap $<0.05$ compared with normal control group (Group 1 ). ${ }^{\text {b }}<0.05$ compared with diabetic control group (Group 2).

Table 2. Hypolipidemic effect of ethyl acetate fraction of Momordica charantia on Streptozotocin-Nicotinamide induced diabetic rats.

\begin{tabular}{|c|c|c|c|c|c|}
\hline Parameter & Normal control & Diabetic control & Diabetic+Glibeclamide & Diabetic+M. charantia & Diabetic+ethyl acetate fraction \\
\hline TG & $61.5 \pm 4.56$ & $142.8 \pm 14.0^{\mathrm{a}}$ & $68.8 \pm 6.4^{\mathrm{ab}}$ & $86.4 \pm 7.40^{\mathrm{ab}}$ & $56.4 \pm 7.40^{\mathrm{ab}}$ \\
\hline TC & $73.6 \pm 6.70$ & $157.0 \pm 11.85^{a}$ & $78.2 \pm 8.21^{\mathrm{ab}}$ & $96.3 \pm 5.3^{b}$ & $68.3 \pm 5.3^{b}$ \\
\hline HDL-C & $47.8 \pm 5.8$ & $40.7 \pm 6.5^{a}$ & $45.5 \pm 6.0^{\mathrm{b}}$ & $37.5 \pm 6.0^{\mathrm{b}}$ & $46.8 \pm 4.0^{\mathrm{b}}$ \\
\hline LDL-C & $13.5 \pm 4.7$ & $87.74 \pm 22.5^{a}$ & $18.94 \pm 4.8^{\mathrm{ab}}$ & $41.52 \pm 11.6^{b}$ & $10.25 \pm 3.6^{b}$ \\
\hline VLDL-C & $12.3 \pm 0.43$ & $28.6 \pm 3.5^{a}$ & $13.76 \pm 2.7^{b}$ & $17.28 \pm 3.7^{a b}$ & $11.25 \pm 1.7^{b}$ \\
\hline $\mathrm{Al}$ & $1.29 \pm 0.33$ & $3.50 \pm 0.83^{a}$ & $1.51 \pm 0.5^{b}$ & $2.31 \pm 0.2^{\mathrm{ab}}$ & $1.21 \pm 0.66^{b}$ \\
\hline CRI & $1.54 \pm 0.12$ & $3.86 \pm 1.4^{a}$ & $1.11 \pm 0.5^{\mathrm{ab}}$ & $2.57 \pm 0.9^{a b}$ & $1.46 \pm 0.32^{b}$ \\
\hline
\end{tabular}

Data is expressed as Mean $\pm \mathrm{SD}$ for six rats in each group. aP $<0.05$ compared with normal control group (Group 1$)$. ${ }^{\text {b }}<<0.05$ compared with diabetic control group (Group 2). LDL-C=TC-TG/5 - HDL-C, VLDL-C = TCHDL-C- LDL-C, AI=TG/HDL-C, CRI=TC/HDL Abbreviations: TG: Triacylglyceride, TC: Total cholesterol, HDL-C: High-density lipoprotein cholesterol, LDL-C: Low-density lipoprotein cholesterol, VLDL-C: Very low-density lipoprotein cholesterol, Al: Atherogenic index, CRI: Coronary risk index.

Table 3. Effect of ethyl acetate fraction of Momordica charantia on some biochemical parameters in Streptozotocin-Nicotinamide induced diabetic rats.

\begin{tabular}{|c|c|c|c|c|c|}
\hline Parameters & Normal control & Diabetic control & Diabetic+Glibeclamide & Diabetic+M. chanratia & Diabetic+ethyl acetate fraction \\
\hline Serum amylase (U/ml) & $383 \pm 21.65$ & $589 \pm 23.90^{\mathrm{a}}$ & $405 \pm 27.22^{\mathrm{ab}}$ & $468 \pm 30.10^{a b}$ & $377 \pm 21.8^{b}$ \\
\hline Liver total protein (mg/ml) & $8.6 \pm 0.82$ & $6.5 \pm 1.0^{\mathrm{a}}$ & $7.6 \pm 0.95^{\mathrm{ab}}$ & $7.0 \pm 1.1^{\mathrm{ab}}$ & $8.4 \pm 0.4^{b}$ \\
\hline Total kidney protein $(\mathrm{mg} / \mathrm{ml})$ & $5.4 \pm 0.89$ & $3.3 \pm 1.50^{\mathrm{a}}$ & $5.3 \pm 1.20^{b}$ & $4.1 \pm 0.87^{\mathrm{ab}}$ & $5.7 \pm 0.83^{\mathrm{ab}}$ \\
\hline Serum creatinine $(\mathrm{mg} / \mathrm{ml})$ & $0.4 \pm 0.67$ & $0.8 \pm 1.94^{a}$ & $0.6 \pm 1.0^{\mathrm{ab}}$ & $0.7 \pm 0.99^{a b}$ & $0.5 \pm 0.69^{a b}$ \\
\hline Serum urea $(\mathrm{mg} / \mathrm{ml})$ & $27.8 \pm 8.55$ & $38.5 \pm 10.21^{a}$ & $30.19 \pm 11.67^{\mathrm{ab}}$ & $31.52 \pm 14.36^{\mathrm{ab}}$ & $30.59 \pm 13.0^{\mathrm{ab}}$ \\
\hline Liver glycogen $(\mathrm{mg} / \mathrm{g})$ liver & $17.34 \pm 0.64$ & $8.3 \pm 0.32^{a}$ & $15.4 \pm 0.71 a^{b}$ & $14.9 \pm 0.77^{\mathrm{ab}}$ & $16.0 \pm 0.51^{b}$ \\
\hline Kidney glycogen mg/g liver & $2.93 \pm 0.41$ & $2.7 \pm 0.5 .4$ & $2.6 \pm 0.69$ & $2.85 \pm 0.71$ & $2.10 \pm 0.77^{\mathrm{b}}$ \\
\hline
\end{tabular}

Data is expressed as Mean \pm SD for six rats in each group. ap $<0.05$ compared with normal control group (Group 1$)$. ${ }^{b} P<0.05$ compared with diabetic control group (Group 2).

\section{Discussion}

The experiment described in this study investigated the hypoglycemic and insulin mimicking effects of ethyl acetate fraction of Momordica charantia on Streptozotocinnicotinamade induced hyperglycemia in rat models. Biochemical profile of the rats was used to assess the hypoglycemic properties of the extract.
Among the physiological functions of insulin is the stimulation of glycogen synthase and inhibition of glycogen phosphorylase, leading to the intracellular storage of glucose as glycogen in the liver and muscle. Various researchers have reported the selective destruction of insulin producing cell of islets of Langerhans by streptozotocin-nicotinamide resulting 
to decline of insulin level and impairment of glucose transport [35-37].

Table 4. Acute toxicity of crude extract of Momordica charantia.

\begin{tabular}{|c|c|c|}
\hline Phases & Dosage (mg/kg body weight) & Mortality \\
\hline \multicolumn{3}{|c|}{ Phase I } \\
\hline Group 1 & 10 & $0 / 3$ \\
\hline Group 2 & 100 & $0 / 3$ \\
\hline Group 3 & 500 & $0 / 3$ \\
\hline \multicolumn{3}{|c|}{ Phase II } \\
\hline Group 4 & 100 & $0 / 3$ \\
\hline Group 5 & 2900 & $0 / 3$ \\
\hline Group 6 & 5000 & $0 / 3$ \\
\hline
\end{tabular}

Our result indicated that intraperitoneal injection of Streptozotocin in the animals caused a significant $(p<0.05)$ increase in blood glucose levels $(\geq 200 \mathrm{mg} / \mathrm{dl})$ associated with marked decreased in the level of liver glycogen, whereas there were no significant change in the level of kidney glycogen. Liver is an insulin dependent organ that plays vital role in regulating glucose homeostasis via the maintenance of the balance between glucose input (glucose uptake and glycogen synthesis) and out (glycogenolysis and gluconeogenesis) [38]. Insulin mediate aforementioned physiological process through different mechanism that may involve: increase in levels of plasma membrane glucose transporter 4 (GLUT4); stimulation of hexokinase and glycogen synthase kinase 3(GSK3); inhibition of glycogen phosphorylase, phosphoenolpyruvate carboxykinase (PEPCK) and glucose-6-phosphatase (G6Pase) [39]. The decrease of liver glycogen may be due to down regulation of GLUT4, hexokinase and GSK3 under the absent of insulin. Kidney is an insulin independent organ that increases the reabsorption of glucose in hyperglycemic condition. The kidney glycogen content in this study indicated that there is inhibition of GSK3 and hexokinase under a low level of insulin. From our findings oral administration of methanolic leaves extract of and the ethyl acetate fraction of Momordica charantia leaves at the same dose of $50 \mathrm{mg} / \mathrm{kg}$ body led to normal levels of plasma glucose level and glycogen in the tissues, thus suggesting that the extract may have exhibited its antidiabetic action either by stimulating insulin release from the pancreatic $\beta$ cell and or by mimicking insulin action. Following oral treatment with these extracts the reduction started on day 7 and continues to fall throughout the period of the experiment with ethyl acetate fraction of Momordica charantia exhibiting highest hypoglycemic effect.

The study also revealed that intraperitoneal injection of Streptozotocin in the animals caused a significant $(p<0.05)$ abnormal lipid profiles characterized by increases in serum triglycerides, total cholesterol, low density lipoprotein accompanied by decrease of serum level of high density lipoprotein (Table 2). The atherogenic index AI, and coronary risk index were also increased significant $(\mathrm{p}<0.05)$ in diabetic rats (Table 2). Treatment with methanolic leaves extract and ethyl acetate fraction of Momordica charantia resulted to a normal levels of this lipid profiles and atherogenic index AI, and coronary risk index. The results indicates that the mechanism of action of the extract is not only due to effective glycemic control but could also due inhibition of triglyceride and cholesterol synthesis via the activation LDL receptors in hepatocytes which increases the rate of LDL clearance. Depression of hormone sensitive lipase could lead to the lipolysis of stored triglyceride in the adipose tissues, liberating free fatty acids (FFA) and increased FFA inhibits muscle phosphorylation of carbohydrates thus leading to hyperglycemia. Increased catabolism of FFA leads to elevated levels of ketone bodies which normally causes ketoacidosis in diabetes. The resulting acetyl-CoA is converted to triglyceride, very low density lipoprotein VLDL and low density lipoprotein leading to dyslipidemia; a predisposing factor for the development of atherosclerosis. Therefore, hyperglycemia has been linked to the pathogenesis of diabetic complication as a result of glycation of collagenous proteins and other proteins, thus causing nephropathy, retinopathy and neuropathy. Indepth considerations of the biochemistry of diabetic complications suggest that there is need to improve and compliment the use of orthodox practice for the treatment of the multifactoria diabetes disease with novel and effective antidiabetic agent without side effect.

In this study, intraperitoneal injection streptozotocinnicotinamide in the rats resulted to a marked decreased in the levels of total protein and albumin in the liver and kidney. This observation might be due to proteinurea and albunuria that are symptoms of diabetic nephropathy resulting from hyperglycemia. It might also due to increase degradation of protein leading to the influx of amino acid into the liver for gluconeogenesis in diabetic conditions [40-42]. Oral administration of ethyl acetate fraction of Momordica charantia at the same dose $50 \mathrm{mg} / \mathrm{kg}$ body weight led to the increase in the liver and kidney total protein and albumin to normal levels. Considering the $\mathrm{A} / \mathrm{G}$ ratio of the animals in Group 5 (diabetic treated with the ethyle acetate fraction of the extract), in comparison to the animals in Group 2 untreated (Diabetic control), it is suggestive that the extract would be effective in the management of proteinurea and albunuria.

From Table 3, the serum levels of urea and creatinine were seen to increase significantly $(p<0.05)$ in diabetic control animals (Group 2), compared to the normal control animals (Group 1) indicating kidney failure and increased deamination of amino acid for adenosine triphosphate production in diabetic situation. Oral administration of ethyl acetate fraction of Momordica charantia at dose of $50 \mathrm{mg} / \mathrm{kg}$ body weight restored the serum levels of urea and creatinine to nearly normal levels.

The serum level of alpha-amylase in this study increased drastically in streptozotocin-nicotinamide induced hyperglycemia as compared to normal rats in Group 1. However, treatment with ethyl acetate fraction of Momordica charantia at dose of $50 \mathrm{mg} / \mathrm{kg}$ body weight orally resulted to a 
significant $(\mathrm{p}<0.05)$ reduction in serum levels of alpha-amylase as compared to the animals in Group 3 that were treated with the standard drug glibenclimide. Contrary to this finding, several researchers have reported positive correlation between streptozotocin induced hyperglycemia and serum alphaamylase [43-45]. In fact some researchers attributed this effect to enhancement of transcription and translation of alphaamylase mRNA [46-48]. Controlling glycemic index and avoiding diabetic complications is very central in the management of hyperglycemia, which is the hallmark of diabetes mellitus. Although the exact mechanism of streptozotocin induction of alpha-amylase is unknown, it is believed to be due high influx of the enzyme into the plasma as a result of destruction of the pancreas by streptozotocin $[49,50]$. It is known that alpha-amylase catalyzes the hydrolysis of $\alpha$ - $(1,4)$-D-glycosidic bond of polysaccharide to smaller polysaccharide and disaccharides, therefore, inhibition of this enzyme retards carbohydrate digestion and the absorption of the resulting monosacchrides thus decreases postprandial serum glucose levels.

\section{Conclusion}

Summarily, this is the first report on antidiabetic properties of ethyl acetate leave extract of Momordica charantia on Streptozotocin-Nicotinamide induced type 2 diabetic rats. Our findings indicated that ethylacetate fraction of the leaves of the plant has antidiabetic activity at dose $50 \mathrm{mg} / \mathrm{kg}$ body weight with comparable potency as that of the antidiabetic standard drug glibenclimide. This is substantiated by the ability of the extract to restore the biochemical indices of the diabetic rats to normal. The most likely pharmacological agent is suggestive of a polar agent, since it was extracted by a polar solvent.

\section{References}

1. Lin Y, Sun Z. Current views on type 2 diabetes. J Endocrinol 2010; 204:1-11.

2. Tripathi BK, Srivastava AK. Diabetes mellitus: complications and therapeutics. Med Sci Monit 2006; 12:130-147.

3. Chen L, Magliano DJ, Zimmet PZ. The worldwide epidemiology of type 2 diabetes mellitus-present and future perspectives. Nat Rev Endocrinol 2011; 8:228-236.

4. Wu Y, Ding Y, Tanaka Y, Zhang W. Risk Factors Contributing to Type 2 Diabetes and Recent Advances in the Treatment and Prevention. Int J Med Sci 2014; 11:1185-1200.

5. Wild S, Roglic G, Green A. Sicree R, King H.. Global prevalence of diabetes: estimate for the year 2000 and projections for 2030. Diabetes Care 2004; 127:1047-1053.

6. Weigensberg MJ, Goran MI. Type 2 diabetes in children and adolescents. Lancet 2009; 373:1743-1744.

7. Ripsin CM, Kang H, Urban RJ. Management of blood glucose in type 2 diabetes mellitus. Am Fam Physician 2009; 79:29-36.
8. Phung OJ, Schwartzman E, Allen RW, Engel SS, Rajpathak SN. Sulphonylureas and risk of cardiovascular disease: systematic review and meta-analysis. Diabet Med 2013; 30:1160-1171.

9. Mamtani R, Haynes K, Bilker WB, Vaughn DJ, Strom BL, Glanz K, Lewis JD. Association between longer therapy with thiazolidinediones and risk of bladder cancer: a cohort study. J Natl Cancer Inst 2012; 104:1411-1421.

10. Kim KS, Kim SK, Sung KM, Cho YW, Park SW. Management of type 2 diabetes mellitus in older adults. Diabetes Metab J 2012; 36:336-344.

11. Kurukulasuriya LR, Sowers JR. Therapies for type 2 diabetes: lowering HbA1c and associated cardiovascular risk factors. Cardiovasc Diabetol 2010; 9:45.

12. World Health Organization. Quality control methods for medicinal plant materials. Geneva: WHO 2002.

13. Saeed S, Tariq P. Antibacterial activities of Mentha piperita, Pisum sativum and Momordica charantia. Pakistan J Botany 2005; 37:997-1001.

14. Anun YS, Adisakwattana S, Yao CY, Sangvanich P, Roengsumran S, Hsu WH. Slow acting protein extract from fruit pulp of Momordica charantia with insulin secretagogue and insulinomimetic activities. Biol Pharm Bull 2006; 29:1126-1131.

15. Bot YS. Screening for the anti HIV properties of the fruit pulp extract of M. balsamina. Ekpoma: Ambrose Alli University 2004.

16. Haque EM, Alam BM, Hossain SM. The efficacy of cucurbitane type triterpenoids, glycosides and phenolic compounds isolated from Momordica charantia: a review. Int J Pharm Sci Res 2011; 2:1135-1146.

17. Ray RB, Raychoudhuri A, Steele R, Nerurkar P. Bitter melon (Momordica charantia) extract inhibits breast cancer cell proliferation by modulating cell cycle regulatory genes and promotes apoptosis. Cancer Res 2010; 70:1925-1931.

18. Adim EU, Dingwoke EJ, Adamude FA, Edenta C, Nwobodo NN, Offiah RO, Onyeka IP, Ezeaku IN. Bacteriostatic and Bactericidal effects of ethyl acetate root bark extract of Terminalia avicennioides on Methicillinresistant Staphylococcus aureus. Afri J Biochem Res 2018; 12:45-54.

19. Lorke D. A new approach to practical acute toxicity testing. Arch Toxicol 1983; 54:275-287.

20. Parasuraman S. Toxicological screening. J Pharmacol Pharmacother 2011; 2:74-79.

21. Masiello P, Broca C, Gross R, Roye M, Manteghetti M, Hillaire-Buys D, Novelli M, Ribes G. Development of a new model of type 2 diabetes in adult rats administered with streptozotocin and nicotinamide. Diabetes 1998; 47:224-229.

22. Banchroft JD, Stevens A, Turner DR. Theory and practice of histological techniques, 4th Edn 1996; Churchil Livingstone, New York, London, San Francisco, Tokyo.

23. Reinhold J. Standard method in clinical chemistry in edited byReiner, M. Academic press New York 1953; 1-88. 
24. Natelson S, Scott ML, Begga E. A rapid method for the estimation of urea in biological fluids by means of the reaction between diacetyl and urea. Am J Clin Pathol 1951; 21:275-281.

25. Roscoe MH. The estimation of Creatinine in Serum. J Clin Path 1953; 6:201-207.

26. Klein B, Foreman JA. Amylolysis of a chromogenic substrate, Cibachron Blue F3GA-amylose: kinetics and mechanism. Clin Chem. 26:250-253.

27. Tietz NW, Finley PR, Pruden EL. Clinical Guide to Laboratory Tests. 2nd Edn. WB Saunders Philadelphia 1990, 304-306.

28. Seidel AD. Policy studies review. Review Policy Res 1983; 3:1541-1338.

29. Sugiuchi H, Uji Y, Okabe H, Irie T, Uekama K, Kayahara N, Miyauchi K. Direct measurement of high-density lipoprotein cholesterol in serum with polyethylene glycolmodified enzymes and sulfated alpha-cyclodextrin. Clin Chem 1995; 41:717-723.

30. Friedewald WT, Levy RI, Fredrickson DS. Estimation of the concentration of low-density lipoprotein cholesterol in plasma, without use of the preparative ultracentrifuge. Clin Chem 1972; 18:499-502.

31. Morita T, Oh-hashi A, Takei K, Ikai M, Kasaoka S, Kiriyama S. Cholesterol-lowering effects of soybean, potato and rice proteins depend on their low methionine contents in rats fed a cholesterol-free purified diet. J Nutr 1997; 127:470-477.

32. Dobiásová M, Frohlich J. The plasma parameter log (TG/ HDL-C) as an atherogenic index: correlation with lipoprotein particle size and esterification rate in apoBlipoprotein-depleted plasma FER, HDL. Clin Biochem 2001; 34:583-588.

33. Alladi S, Shanmugasundaram KR. Induction of hypercholesterolemia by supplementing soy protein with acetate generating amino acids. Nutri Reports Int'l 1989; 40: 893-900.

34. Maiti R, Jana D, Das UK, Ghosh D. Antidiabetic effect of aqueous extract of seed of Tamarindus indica in streptozotocin-induced diabetic rats. J Ethnopharmacol 2004; 92: 85-91.

35. Ashcroft FM, Rorsman P. Diabetes mellitus and the beta cell: the last ten years. Cell 2012; 148, 1160-1171.

36. Bonnefond A, Froguel P, Vaxillaire M. The emerging genetics of type 2 diabetes. Trends Mol Med 2010; 16: 407-416.

37. Bonner-Weir S, Li WC, Ouziel-Yahalom L, Guo L, Weir GC, Sharma A. Beta-cell growth and regeneration: replication is only part of the story. Diabetes 2010; 59:2340-2348.

38. Huang S, Czech MP. The GLUT4 glucose transporter. Cell Metab 2007; 5:237-252.

39. O'Brien, PJ, Herschlag D. Functional interrelationships in the alkaline phosphatase superfamily: phosphodiesterase activity of Escherichia coli alkaline phosphatase. Biochem 2001; 40:5691-5699.

40. Bhavpriya V, Govindasamy S. Biochemical studies on the hypoglycaemic effect of Aegle marmelos corr Roxb in streptozotocin induced diabetic rats. Indian Drugs 2000; 37:474-477.

41. Satirapoj B, Kaewput W, Supasyndh O, Ruangkanchanasetr P, Effect of sulodexide on urinary biomarkers of kidney injury in normoalbuminuric type 2 diabetes: A Randomized Controlled Trial. J Diabetes Res 2015; 172038.

42. Pereira LV, Shimizu MH, Rodrigues LP, Leite CC, Andrade $\mathrm{L}$, Seguro AC. N-acetylcysteine protects rats with chronic renal failure from gadolinium-chelate nephrotoxicity. PLoS One 2012; 7:e39528.

43. Solorzano GT, Silva MV, Moreira SR, Nishida SK, Kirsztajn GM. Urinary protein/creatinine ratio versus 24hour proteinuria in the evaluation of lupus nephritis. J Bras Nefrol 2012; 34:64-67.

44. Abdul-Ghani MA, Tripathy D, DeFronzo RA. Contributions of $\beta$-cell dysfunction and insulin resistance to the pathogenesis of impaired glucose tolerance and impaired fasting glucose. Diabetes Care 2006; 5: 1130-1139.

45. Aughsteen AA, Khair AB, Suleiman AA. Quantitative morphometric study of the skeletal muscles of normal and streptozotocin-diabetic rats. J Pancr 2006; 7:382-389.

46. Schimmer BP, Parker KL. Adrenocorticotropic hormone; adrenocortical steroids and their synthetic analogs; inhibitors of synthesis and actions of adrenocortical hormones. In: Hardman JG, Limbard LE, Gilman AG, Goodman-Gilman A, (eds), Goodman \& Gilman's Pharma Basis Therap. McGraw-Hill 2001; 1658-1659.

47. Wang ZQ, Ribnicky D, Zhang XH, Raskin I, Yu Y, Cefalu WT. Bioactives of Artemisia dracunculus L. enhance cellular insulin signaling in primary human skeletal muscle culture. Metab 2008; 57: 58-64.

48. Patel V, Rahman A, Jacob KS, Hughes M. Effect of maternal mental health on infant growth in low income countries: new evidence from South Asia. BMJ 2004; 328:820-823.

49. Rees DA, Alcolado JC. Animal models of diabetes mellitus. Diabet Med 2005; 22: 359-370.

50. Szkudelski T. The mechanism of alloxan and streptozotocin action in B cells of the rat pancreas. Physiol Res 2001; 50: 537-546.

\section{*Correspondence to}

Emeka John Dingwoke

Faculty of Life Sciences

Department of Biochemistry

Ahmadu Bello University

Nigeria 